\title{
Estimating Reservoir Sedimentation at Large Dams in India
}

\author{
David C. Froehlich ${ }^{1}$ \\ ${ }^{1}$ Consulting Engineer, 303 Frenchmans Bluff Drive, Cary, North Carolina 27513, The USA.
}

\begin{abstract}
Mathematical expressions are developed that relate the storage capacity loss of reservoirs in India to the catchment area, the reservoir surface area, the original storage volume, and the time since the first filling of the impoundment. The relations for sedimentation of reservoirs found on eastward and westward flowing rivers differ significantly, because of meteorological and geological influences on land surface runoff and sediment yield within reservoir catchments. The formulations give good fits to the assembled data and allow an uncomplicated calculation of the half-life of reservoirs (that is, the time needed for the storage capacity to be reduced by $50 \%$ ), which offers a measure of when sedimentation will have a significant adverse impact on the functioning of dams.
\end{abstract}

\section{Introduction}

Eroded sediment transported by natural streams tends to settle out when it enters the comparatively calm water of an artificial lake (a reservoir) created by a dam to store the water. The rate of water storage loss depends on the annual sediment load carried by the streams and the extent to which that material is kept in the reservoir. The amount of sedimentation is controlled by a number of factors including the area and geologic origin of the catchment, the land uses (cultivation practices, grazing, logging, construction activities, and conservation practices), the amount of rainfall, the reservoir storage capacity, the duration of storage in relation to the sediment load of the stream, the particle size distribution of the suspended sediment, the planform configuration of the reservoir, the location and size of sluices and other outlet works at the dam, and the method and purpose of water releases through those outlets.

As time passes, a reservoir continues to fill with sediment, which reduces the available storage volume and may interfere with the operation of dam outlet works and hydropower intake structures (Figure 1). The question is, how long will it take before the functions of the dam and its reservoir are so severely affected by sedimentation that continued operation becomes untenable?

The rate of sedimentation in a proposed or existing reservoir may be estimated in the following ways [1]: 
1. From sediment discharge rating curves combined with flow-duration relations on significant streams entering the reservoir. The sediment discharge rating curves may be prepared using measured or calculated values of sediment loads.

2. From calculations of the total amount of land surface erosion, the ability of the sediment to be transported to the reservoir, and the reservoir trapping efficiency.

3. From predictions based on sedimentation in existing reservoirs in which the accumulated deposits have been surveyed over a lengthy period.

It is the third approach that is followed here based on an evaluation of sedimentation in existing reservoirs in which the accumulated deposits have been surveyed over an extended period. The data are obtained from a compendium of storage loss from siltation at 243 reservoirs in India [1]. Mathematical models are developed that relate reservoir capacity loss to catchment area, reservoir surface area, the original storage volume, and the time since the first filling of the impoundment. Models prepared for sedimentation of reservoirs found on the eastward and the westward flowing regions differ significantly. The formulations give good fits to the assembled data and allow an uncomplicated calculation of the half-life of reservoirs (that is, the time needed for the storage capacity to be reduced by $50 \%$ ), which offers a measure of when sedimentation will have a significant adverse impact on functioning.

\section{Stages of Reservoir Sedimentation}

The proportion of a river's total sediment load captured by a reservoir - known as its "trap efficiency" - approaches $100 \%$ for many projects, mainly when the storage capacity is significant in relation to the annual inflow of water. As sediment accumulates in a reservoir, the dam gradually loses its ability to store water for the purposes for which it was built. The rate of reservoir sedimentation depends primarily on the size of a reservoir in comparison to the amount of sediment flowing into it: A small reservoir on an extremely muddy river will rapidly lose capacity; in contrast, a massive reservoir on a very clear river may take centuries to lose an appreciable amount of storage.

Most dams are designed so that they can afford to lose some storage capacity without their performance diminishing. Conceptually, this is the part of a reservoir known as "dead storage," that is, the storage volume that lies beneath the elevation of the dam's lowest outlet. However, sediments do not build up evenly along a horizontal plane, so that

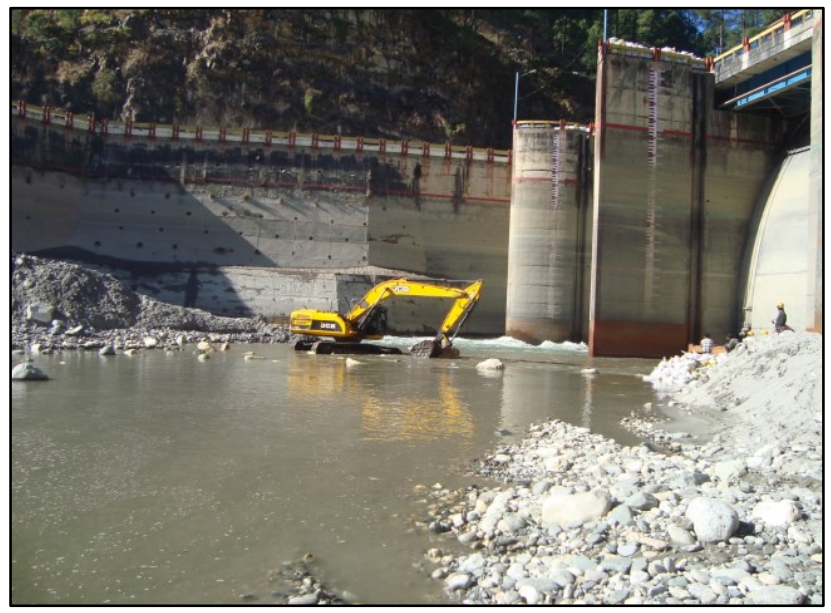

Fig 1. Sediment accumulation reduces storage volume and may interfere with the operation of dam outlet works. Removal of sediment by dredging or excavation (as shown in the photograph) may be needed to enable the dam to function. 
some "live storage" is occupied long before the dead storage is filled. The actual process of sediment deposition is unique to every reservoir and is difficult to predict accurately. In general, the coarser, heavier sediments - the gravel and sand - tend to settle out at the upper end of a reservoir, forming a "backwater" delta that gradually advances toward the dam. The lighter sediments - the silt and clay - tend to deposit in shallow areas along the shoreline of a reservoir and in the deeper regions nearer the dam where velocities are small. Some of the smaller sized particles stay in suspension and will flow through/over the outlet structures.

Knowledge of both the rate and pattern of sediment deposition in a reservoir is needed to predict the specific adverse effects that will occur, the period in which they will happen, and the types of remedial measures that are possible. The following three distinct stages of sedimentation take place once the reservoir begins to fill [3, page 2.14]:

Stage 1. Continuous sediment trapping. During the first stage of reservoir sedimentation, sediment is captured with little material being carried through the impoundment during all large inflows. The deepest parts of the reservoir that are always submerged fill first. Continued deposition eventually produces a flat reservoir bottom.

Stage 2. Partial sediment balance. During the second stage, the reservoir changes from a continuously depositional environment to a mixed regime of deposition and removal. If sedimentation goes ahead uninterrupted, the reservoir at this stage will fill, and a channel-floodplain configuration will develop in the former pool area. The inflow and discharge of fine sediment may balance, but coarse bed material continues to accumulate. Sediment management techniques, such as drawdown to pass sediment-laden flood flows through the impounded reach, or periodic flushing can produce a partial sediment balance to help preserve useful reservoir capacity.

Stage 3. Full sediment balance. A long-term balance between sediment inflow and outflow occurs when both the fine and the coarse portions of the inflow are transported beyond the dam or are removed artificially on a sustainable basis. However, sediment movement through the reservoir is not necessarily the same as the pre-impoundment condition because the material may accumulate during normal stream flows and wash out during floods, or it may be removed at intervals by dredging or flushing.

Most reservoirs in India are in Stage 1, continuously trapping sediment.

\section{Concepts of Reservoir Life}

The traditional approach in the design of dams in to provide sufficient "dead storage" (that is, storage volume beneath the lowest outlet level from which water cannot be released by the usual means) to account for from 50 to 100 years of sediment accumulation [3, Chapter 5]. However, sediment settles out at all levels of a reservoir, not just within deepest portions, which affects all storage allocations by use (that is, conservation, multi-use, or flood control).

Reservoirs usually are designed and operated on the concept of a finite life which will ultimately be terminated by sediment accumulation rather than structural obsolescence. The problem confronting project planners is to estimate the rate of deposition and the period before sediment will interfere with the useful functioning of a reservoir. At the time of design, provisions should be made for enough sediment storage in a reservoir so as not to impair its functions during the intended life of the project. 
The life of a reservoir depends primarily on its storage capacity loss caused by sedimentation. Several concepts of reservoir life used to plan and design a project (as adapted from [4] and [5] are summarized below:

1. Design life is the period used when planning a project to assess the economic benefits. Economic evaluations are typically based on a period not exceeding 50 years, while engineering studies often incorporate a 100-year lifespan for the design.

2. Project life (also called useful life) is the period during which the reservoir can reliably satisfy the purposes for which it was built. When the reservoir can no longer serve its intended use because of sediment accumulation, it has reached the end of its design project life. However, the operation may continue with a revised or scaled-down project design. Given the probabilistic nature of hydrologic events, the definition of project "failure" should be based on the relationship between declining storage volume and reliability. Severe interference with the original project design can be expected by the time half the storage capacity has been lost because of sediment deposition. In some cases, sediment accumulation affects reservoir operation when only a small fraction of the original storage capacity has been lost.

3. Economic life is the period over which the economic benefits from project operation exceed costs. Continued operation of a project is economically justified if the present value of the project benefits exceeds that of project costs, following the principles of engineering economy.

4. Usable life is the period during which the reservoir may be operated for either its original or a modified purpose, whether such use generates net economic benefits.

5. Full life is the period during which reservoir capacity is completely lost because of sedimentation.

Standard practice is to calculate the reservoir life by dividing the usable storage volume by the average amount sediment deposited annually. However, in many reservoirs, the economic life is reached when the useful storage volume varies from $50 \%$ to $80 \%$ of the original total capacity [4, page 1]. Consequently, reservoir half-life T50\%, the time needed to lose half the original capacity to sedimentation, may offer a better measure of when sedimentation will have a significant impact on functioning [3].

\section{Analysis of Reservoir Capacity Loss and Half-Life}

The amount of sediment deposited in a reservoir increases as the average amount of time that water spends in the impoundment before exiting (that is, the residence time) lengthens. Residence time increases with reservoir capacity and decreases as the catchment runoff increases. Where the storage volume of a reservoir is large in comparison to the annual runoff from the catchment (that is, where the capacity-inflow ratio is sizeable), nearly all the sediment carried by inflowing streams will be retained in the impoundment. When the runoff of the catchment of reservoir is substantial in comparison to the reservoir capacity (a small capacity-inflow ratio), the reservoir discharges the surplus freely for extended periods, and it is possible that a considerable proportion of the sediment in suspension may be carried downstream with the surplus water, but the bedload and a part of suspended sediment will be deposited in the reservoir.

Estimating the amount of sedimentation in a reservoir could require extensive calculations of the sediment yield from the catchment, the amount of eroded soil that 


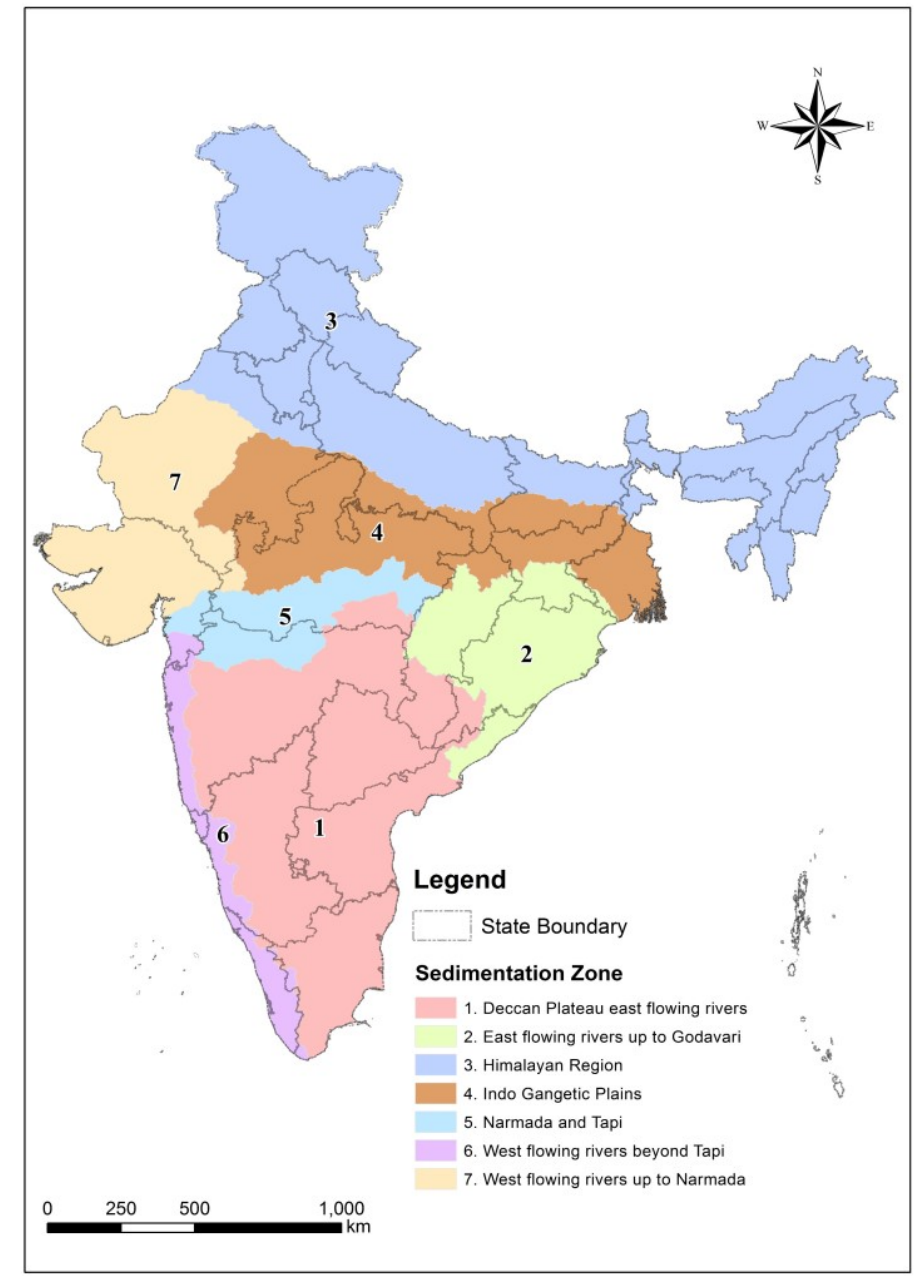

Fig 2. Sedimentation Zones of India as presented in [2].

actually is transported to a reservoir, the additional sediment inflow contributed by stream channel bank and bed erosion, and the quantity of water that flows into the reservoir. However, a more simple and faster approach to estimating reservoir sedimentation is developed here by analyzing data from the compendium of siltation at 243 reservoirs in India [2] where the accumulated deposits have been surveyed over a suitable period. The compendium divides India into seven sedimentation zones as shown in Figure 2. Zones 1, $2,3 \& 4$ cover geographic regions in which rivers flow eastward to the Bay of Bengal, while Zones 5, $6 \& 7$ encompass areas where rivers flow westward into the Arabian Sea.

\subsection{General Form of Capacity Loss Model}

For both eastward and westward-flowing rivers, a general mathematical model of the form

$$
\ln \hat{Y}=\theta_{1}+\theta_{2} \ln A_{c}+\theta_{3} \ln A_{r}+\theta_{4} \ln C_{o}+\theta_{5} \ln T
$$

provides a linear relation for $\ln \hat{Y}$ with constant variance and good fits to the assembled data, where $\hat{Y}=$ expected value of reservoir capacity loss in $\mathrm{Mm}^{3}, A_{c}=$ catchment area in 
$\mathrm{km}^{2}, A_{r}=$ surface area of the reservoir when filled to the controlled retention level (FRL) in $\mathrm{km}^{2}, C_{o}=$ initial storage capacity of the impoundment in $\mathrm{Mm}^{3}$, and $T=$ time in years since the initial filling of the reservoir. Values of the parameters $\theta_{1}$ to $\theta_{5}$ were found using multivariate optimization.

\subsection{Reservoirs on Eastward Flowing Rivers (Sedimentation Zones 1, 2, 3 \& 4)}

The best mathematical model for capacity loss in reservoirs found on eastward flowing rivers $Y_{\text {east }}$ is obtained with $\theta_{1}=-5, \theta_{2}=0.10, \theta_{3}=0.05, \theta_{4}=0.8$, and $\theta_{5}=0.9$, where values of parameters were rounded slightly. Inserting the best-fit values in Eq. (1) gives

$$
\ln \hat{Y}_{\text {east }}=-5.05+0.10 \ln A_{c}+0.05 \ln A_{r}+0.8 \ln C_{o}+0.9 \ln T
$$

The coefficient of determination of Eq. (2) is $r_{\ln Y_{\text {east }}}^{2}=0.929$, and the residual standard error is $s_{\ln Y_{\text {east }}}=0.600$. Predicted values of $Y_{\text {east }}$ are plotted against measured values in Figure 3. Rearranging Eq. (2) gives the more manageable expression

$$
\hat{Y}_{\text {east }}=0.0064 A_{c}^{0.10} A_{r}^{0.05} C_{o}^{0.8} T^{0.9}
$$

\subsection{Reservoirs on Westward Flowing Rivers (Sedimentation Zones 5, 6 \& 7)}

For reservoirs on westward-flowing rivers, the best mathematical model for capacity loss is obtained with $\theta_{1}=-3.5, \theta_{2}=0.15, \theta_{3}=0.30, \theta_{4}=0.50$, and $\theta_{5}=0.65$, where parameter values $\left(\theta_{1}\right.$ to $\left.\theta_{5}\right)$ again were rounded slightly. Inserting the best-fit values in Eq. (1) gives

$$
\ln \hat{Y}_{\text {west }}=-3.5+0.15 \ln A_{c}+0.30 \ln A_{r}+0.50 \ln C_{o}+0.65 \ln T
$$

The coefficient of determination of Eq. (4) is $r_{\ln Y_{\text {east }}}^{2}=0.880$, and the residual standard error is $s_{\ln Y_{\text {east }}}=0.496$. Predicted values of $Y_{\text {west }}$ are plotted against measured values in

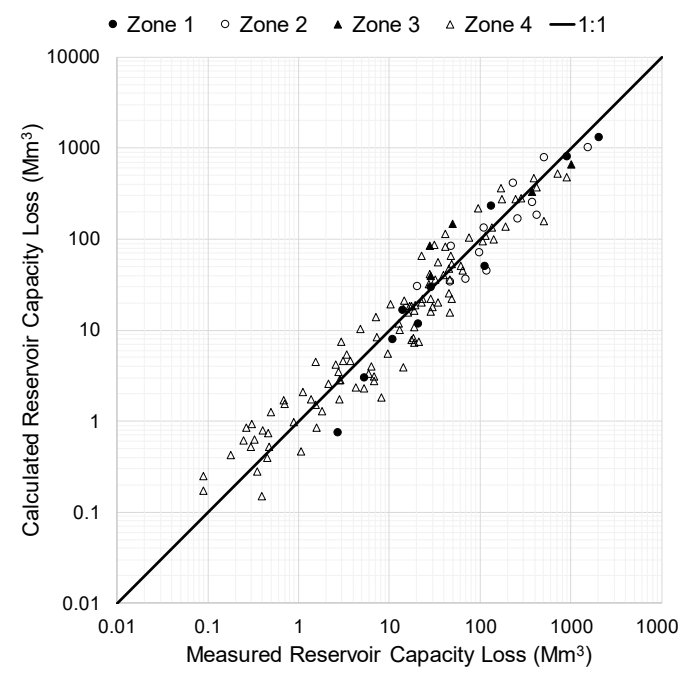

Fig. 3. Comparison of measured and calculated reservoir capacity loss in reservoirs on eastward flowing rivers in sedimentation zones $1,2,3 \& 4$. 


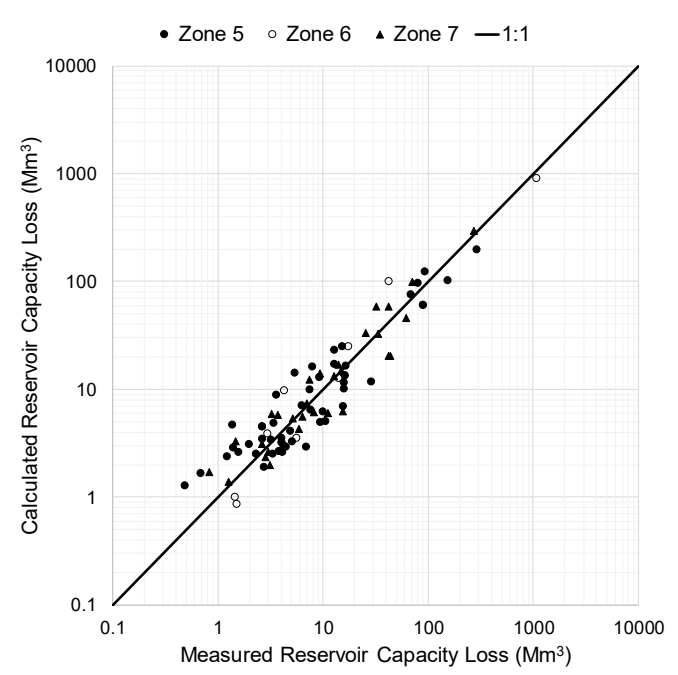

Fig. 4. Comparison of measured and calculated reservoir capacity loss in reservoirs on westward flowing rivers in sedimentation zones $5,6 \& 7$.

Figure 4. Rearranging Eq. (4) gives

$$
\hat{Y}_{\text {west }}=0.030 A_{c}^{0.15} A_{r}^{0.30} C_{o}^{0.50} T^{0.65}
$$

\subsection{Discussion of Capacity Loss Relations}

The expression for $Y_{\text {east }}$ shows that reservoir capacity loss grows as all the independent variables $\left(A_{c}, A_{r}, C_{o}\right.$, and $\left.T\right)$ increase. Sediment inflow to a reservoir will increase as the size of the catchment increases, and the average residence time will increase with $C_{o}$, both factors causing greater storage loss. For a given initial capacity, average water depth in a reservoir is reduced as surface area increases, which allows more suspended sediment to settle within the impoundment.

Because of the exponent of $T$ in Eqs. (3) and (5) being less than one, the rate at which capacity is lost is a decreasing function of time. This is expected because those areas of the reservoir that are conducive to the settlement of fine-grained sediments will fill quickly in the early years and then no longer be available for deposition. Shrinkage of deposited silt also takes place from weathering action and the superimposed loads of additional sediment thereby reducing the sedimentation rate with time.

The expression for the loss of reservoir storage volume on westward flowing rivers $Y_{\text {west }}$ varies significantly from the equation for $Y_{\text {east }}$. While the relative influence of $A_{c}$ is the same, the remaining independent variables have many different effects on reservoir capacity loss. The most significant difference is related to time. All other factors being the same, capacity loss of reservoirs on westward flowing rivers slows considerably faster than on eastward flowing rivers resulting in a comparatively longer half-life. Regional reservoir sedimentation differences are the result of combined meteorological and geological influences on land surface runoff and sediment yield. 


\subsection{Reservoir Half-Life Calculation}

Reservoir half-life, the time expected for $50 \%$ of the usable reservoir storage capacity to be filled with sediment, is determined from Eq. (1) by setting $Y / C_{o}=0.5$ and solving for $T$ to obtain

$$
T_{50 \%}=\left[\frac{0.5}{\exp \left(\theta_{1}\right)} A_{c}^{-\theta_{2}} A_{r}^{-\theta_{3}} C_{o}^{\left(1-\theta_{4}\right)}\right]^{1 / \theta_{5}}
$$

Substituting optimal values of the parameters $\theta_{1}$ to $\theta_{6}$ determined for reservoirs on eastward and westward flowing rivers gives

$$
T_{50 \%}(\text { years })=\left\{\begin{array}{l}
{\left[74.2 A_{c}^{-0.15} A_{r}^{-0.1} C_{o}^{0.3}\right]^{1.11} ; \text { reservoirs on eastward flowing rivers }} \\
{\left[16.6 A_{c}^{-0.15} A_{r}^{-0.3} C_{o}^{0.5}\right]^{1.54} ; \text { reservoirs on westward flowing rivers }}
\end{array}\right.
$$

A brief example illustrates the regional difference on the calculation of $T_{50 \%}$ for a proposed reservoir where $C_{o}=80 \mathrm{Mm}^{3}, A_{c}=200 \mathrm{~km}^{2}$, and $A_{r}=5 \mathrm{~km}^{2}$. Inserting variables in Eq. (7) gives

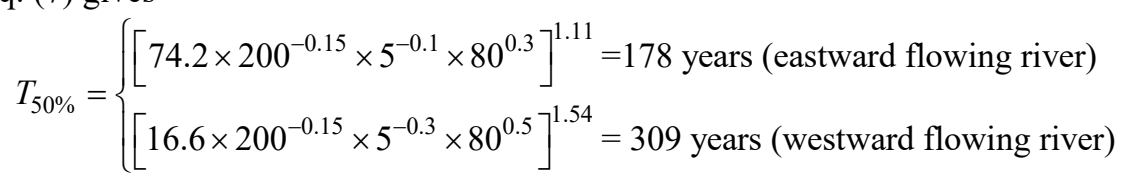

\section{Summary and Conclusions}

Mathematical models are presented that relate reservoir capacity loss to catchment area, reservoir surface area, initial storage volume, and time since the initial filling of the impoundment. Two models are developed, one for reservoirs on eastward flowing rivers, and one for westward flowing regions. The expression for the loss of reservoir storage volume on westward flowing rivers $Y_{\text {west }}$ varies significantly from the equation for $Y_{\text {east }}$, because of the joint meteorological and geological influences on land surface runoff and sediment yield.

The formulations give good fits to the assembled data, and allow an uncomplicated calculation of the half-life of reservoirs (that is, the time needed for initial storage capacity to be reduced by $50 \%$ ), which provides a measure of when sedimentation will have a significant adverse impact on functioning. The formulas give a straightforward and rapid means of estimating the loss of reservoir storage capacity because of sediment deposition.

\section{References}

1. Bureau of Indian Standards, Indian Standard IS 6518:1992c (1992)

2. Central Water Commission, Compendium on silting of reservoirs in India, Ministry of Water Resources, Watershed and Reservoir Sedimentation Directorate, New Delhi, India (2015).

3. Morris, G.L., and Fan, J., Reservoir sedimentation handbook. McGraw-Hill, New York, New York (1998).

4. Murthy, B.N., Technical Report No. 19, Central Board of Irrigation and Power, New Delhi, India (1980).

5. Gill, M.A., Journal of Hydrology, 44(1/2), 89-95.

6. Mahmood, K. Technical Report No. 71, The World Bank, Washington, D.C. (1987). 